\title{
CHANGES IN OXYGEN LEVEL UPON COLD PLASMA TREATMENTS: CONSEQUENCES FOR RONS PRODUCTION
}

\author{
Giovanni Busco ${ }^{1 *}$, Fabienne Fasani ${ }^{1}$, Sébastien Dozias ${ }^{2}$, Loïck Ridou${ }^{1}$, Claire Douat ${ }^{2}$, Jean-Michel Pouvesle ${ }^{2}$, Eric \\ Robert $^{2}$, and Catherine Grillon ${ }^{1}$
}

\begin{abstract}
Despite the large number of papers showing the biological effect of Cold Atmospheric Plasmas (CAPs) on skin treatment and although their ability to produce a cocktail of reactive oxygen and nitrogen species is largely known, the deep knowledge of these ionized gas sources is far to be uncovered. Many parameters take part in the complex mechanisms induced by plasma, such as voltage, frequency, feeding gas flow rate, temperature, air humidity and atmospheric gas composition. In this work we focus our attention on the influence of oxygen dissolved in the medium in reactive oxygen and nitrogen species (RONS) generation during CAP treatment. We evaluate RONS production in Dulbecco's Phosphate-Buffered Saline equilibrated with two different percentages of oxygen: $18 \%$ and $3 \% \mathrm{O}_{2}$. The former oxygen concentration is that usually used in most of cell culture and treatment (normoxia) while the latter is close to the physiological level measured inside human skin (physioxia). Intracellular RONS generation upon CAP treatment was also measured in two human skin cell lines maintained either in normoxic or in physioxic conditions. Our data suggest that RONS generation induced by plasma either in the medium or inside cells is influenced by oxygen dissolved in the treated target.
\end{abstract}

Index Terms - Non-equilibrium plasma sources, Plasma-liquid interactions, Plasma-cell interactions, Oxygen, RONS.

\section{INTRODUCTION}

$\mathrm{T}$ HE different cell types composing human body, with their heterogeneous metabolism and blood supply, create a microenvironment that is characteristic of each tissue. Chemical and physical extracellular parameters act together to create a unique, organ-specific, physiological condition.

Among the factors influencing the extracellular microenvironment, oxygen plays a relevant role. Its local partial pressure is a typical signature that varies from one tissue to another. Organ physiological oxygenation is called physioxia and ranges between $14.5 \%$ in pulmonary alveoli and
$1 \%$ in hair follicles [1]. However, in vitro cell cultures are currently performed in classic incubator under atmospheric oxygen pressure conditions $\left(37^{\circ} \mathrm{C}, 5 \% \mathrm{CO}_{2}\right.$ and $95 \%$ of air, i.e. $18-19 \% \mathrm{O}_{2}$ ). This gas level is far from the physiological oxygenation of any human tissue and this has consequences on cell activities [1-3]. Attempts have to be done to respect tissue physioxia in vitro, especially to avoid excess of oxidative stress. In fact, although oxygen is of vital importance for aerobic organisms, it possesses a dark side. During mitochondrial respiration, thanks to oxygen, cells produce and store energy in one hand and create toxic catabolites in the other hand. The oxygen derived catabolites are called Reactive Oxygen Species (ROS). Despite their well-known toxicity when produced in high level, ROS also display beneficial effects protecting cells from pathogens or activating signaling pathways [4-6]. In physiological conditions, ROS are kept at the right amount by the cellular antioxidant system. When ROS production overcomes the anti-oxidant defenses, it induces an oxidative stress that can lead to pathological effects on the organism [4, 7-9]. Cold atmospheric plasma (CAP) is known to generate reactive oxygen and nitrogen species (RONS). Depending on the treated cell type and on the treatment conditions, plasmadelivered reactive species can generate opposite effect: stimulate normal cell growth or induce apoptosis in tumor cells [10-12]. At the molecular level, RONS are generated by plasma directly inside the ionized gas but also by interactions with the liquid with which it comes in contact [13]. Despite the wellknown importance of oxygen in RONS production, the role of oxygen partial pressure in the medium or in in vitro cell culture has almost not been taken into account in the study of CAP mechanisms and its biological effects [14]. Here we show the effect of our He-Plasma Gun on dissolved oxygen in a treated Dulbecco's Phosphate-Buffered Saline (DPBS), on ROS and nitrite generation in the medium and finally on intracellular RONS generation in two human skin cell lines maintained in an atmosphere containing either $18 \%$ or $3 \% \mathrm{O}_{2}$.

\section{MATERIALS AND METHODS}

\section{Materials}

giovanni.busco@cnrs-orleans.fr) is funded by the PLASMACOSM project $\mathrm{N}^{\circ}$ 2015-00103497 from Cosmetosciences.

${ }^{1}$ Centre de Biophysique Moléculaire, UPR4301 CNRS rue Charles Sadron, 45071 Orléans, France

${ }^{2}$ GREMI, UMR 7344 CNRS-Université d'Orléans, France. research program dedicated to the cosmetic industry. Located in the heart of the Cosmetic Valley, this program led by University of Orléans is funded by the Région Centre-Val de Loire, France.

*Giovanni Busco postdoc fellow at the Centre de Biophysique Moleculaire, UPR4301 CNRS, rue Charles Sadron, 45071 Orléans, FRANCE (e-mail: 
$2^{\prime}, 7^{\prime}$-dichlorodihydrofluorescein diacetate (DCDHF-DA) was from Molecular Probes ${ }^{\circledR}$ (Thermo Fisher Scientific). Dulbecco's Phosphate-Buffered Saline (DPBS) (GIBCO®) was supplemented with $1 \mathrm{mM} \mathrm{CaCl} 2$ and $0.5 \mathrm{mM} \mathrm{MgCl}_{2}$. N-(1Naphthyl) ethylene-diamine dihydrochloride (NEDD), sulfanilamide and methylene blue were purchased from SIGMA Aldrich.

\section{Plasma Gun device and treatment}

The plasma jet used in this work is delivered by the so-called Plasma Gun (PG) [15]. The plasma is generated in a dielectric barrier discharge reactor based on a glass tube, $4 \mathrm{~mm}$ inner diameter, flushed with a moderate rare gas flow, and equipped with an inner hollowed powered electrode and an outer grounded annular electrode. Ionization wave allows for plasma propagation in the capillary, $10 \mathrm{~cm}$ in length in this work, before expansion in the ambient air where plasma plume emerges at the capillary outlet. The glass tube inner diameter is tapered to $1.5 \mathrm{~mm}$ in the $2 \mathrm{~cm}$ wide section at the outlet of the capillary. In this work, negative polarity high voltage pulses having a peak amplitude of $-14 \mathrm{kV}$, full with half maximum $2 \mu \mathrm{s}$ duration, and delivered at frequency ranging from $250 \mathrm{~Hz}$ to 2 $\mathrm{kHz}$ have been used, while helium gas flow rate was set either at 0.5 or $1 \mathrm{~L} / \mathrm{min}$. Plasma treatments were performed for 60 seconds.

\section{Oxygen partial pressure and temperature measurements}

Oxygen partial pressure $\left(\mathrm{pO}_{2}\right)$ and temperature variations in DPBS were measured during plasma treatment by a calibrated OxyLite fiber optic sensor coupled with a T-type thermocouple (OxyLite $^{\mathrm{TM}}$ probe, $\mathrm{pO}_{2}-$ Series Sensor, BF/OT/E, Oxford Optronix Ltd., Oxford, U.K.). The oxygen sensor is based on the ruthenium fluorescence lifetime decay, which is inversely proportional to the $\mathrm{pO}_{2}$ dissolved in the medium. In order to measure $\mathrm{pO}_{2}$ and temperature, the probe was inserted inside a micro-well of a 96 well plate containing $200 \mu \mathrm{L}$ of DPBS equilibrated at $18 \%$ or $3 \% \mathrm{O}_{2}$ (Fig. 1a). The microwell plate was placed inside a plate heater set at $37^{\circ} \mathrm{C}$. Room temperature was between 22 and $24^{\circ} \mathrm{C}$. Data were recorded by the OxyLite ${ }^{\mathrm{TM}}$ 2000E $\mathrm{pO}_{2}$ (Oxford Optronix Ltd).

\section{Cell culture}

$\mathrm{HaCaT}$ cell line comes by spontaneously immortalized human keratinocytes [16]. MSU 1.1 cell line was obtained by v-myc oncogene transformation of foreskin fibroblast [17]. HaCaT and MSU 1.1 were cultured at $37^{\circ} \mathrm{C}$ in an incubator with $5 \%$ $\mathrm{CO}_{2}$ and $95 \%$ air atmosphere $\left(18 \% \quad \mathrm{O}_{2}\right)$ or inside the HypOxystation incubator (HypOxystation ${ }^{\circledR} \mathrm{H} 35$, Don Whitley Scientific) at $37^{\circ} \mathrm{C}$ in a $5 \% \mathrm{CO}_{2}, 3 \% \mathrm{O}_{2}$ and $92 \% \mathrm{~N}_{2}$ atmosphere). All cells were cultured in high glucose DMEM supplemented with $10 \%$ of fetal bovine serum (FBS), 100 $\mathrm{U} / \mathrm{mL}-100 \mu \mathrm{g} / \mathrm{mL}$ of penicillin-streptomycin (Invitrogen) and 2 $\mathrm{mM}$ of L-Glutamine (Eurobio).

\section{Measurement of nitrites by Griess test}

$200 \mu \mathrm{l}$ of DPBS previously equilibrated at $18 \%$ or $3 \% \mathrm{O}_{2}$ were treated by CAP in a 96-well microplate. Low oxygen concentration in DPBS (3\%) was maintained by means of micro-caps placed on each well, caps were removed for the treatment and immediately replaced. Experiments with airbubbled DPBS were carried out using a peristaltic pump delivering air $(0.24 \mathrm{~mL} / \mathrm{min})$ inside the micro-wells during the whole treatment by means of a capillary tube. After treatment, $40 \mu 1$ of medium from each well were transferred in a new 96well microplate and $80 \mu \mathrm{l}$ of sulfanilamide $3 \mathrm{mM}$ solution and $80 \mu \mathrm{l}$ of NEDD $0.2 \mathrm{mM}$ were added to each well to start the reaction. $\mathrm{NaNO}_{2}$ standard solutions were used to make a calibration curve. After $10 \mathrm{~min}$ of incubation, absorbance of the pink color developed in the presence of nitrites was measured at $560 \mathrm{~nm}$ with a microplate reader spectrofluorometer (Victor ${ }^{3}$ $\mathrm{V}$, PerkinElmer®).

\section{Reactive oxygen species measurement}

Reactive oxygen species formation such as $\mathrm{O}_{3}, \mathrm{O}_{2}{ }^{-}, \mathrm{O}_{2}{ }^{2-}$ and 'OH were measured by methylene blue discoloration. $200 \mu \mathrm{l}$ of DPBS solution containing $0.01 \mathrm{~g} / \mathrm{L}$ of methylene blue and previously equilibrated at $18 \%$ or $3 \% \mathrm{O}_{2}$ were submitted to plasma in a 96-well microplate. Absorbance was read at $664 \mathrm{~nm}$ with the microplate reader spectrofluorometer. As ROS production is inversely proportional to methylene blue absorbance, arbitrary relative values were calculated as OD not treated /OD treated.

\section{Measurement of RONS inside cells}

Intracellular RONS formation upon plasma treatment was measured by the DCDHF-DA probe. The molecule penetrates cell membranes and is hydrolyzed by cell esterases to $2^{\prime}, 7^{\prime}$ dichlorodihydrofluorescein (DCDHF) and then oxidized by intracellular RONS to give $2^{\prime}, 7^{\prime}$-dichlorofluorescein (DCF), a highly fluorescent compound.

Cells $\left(1.5 \times 10^{4} /\right.$ well $)$ were seeded in 96-well microplates and placed in the incubator at $18 \%$ or $3 \% \mathrm{O}_{2}$ for $15 \mathrm{~h}$. The day after, cells were washed with DPBS and then incubated with DCDHF-DA $10 \mu \mathrm{M}$ in DPBS for 20 minutes at $37^{\circ} \mathrm{C}$ in $18 \%$ or $3 \% \mathrm{O}_{2}$. Cells were washed twice with DPBS to remove the excess of extracellular probe. Each well was filled with $200 \mu \mathrm{l}$ of DPBS previously equilibrated at the corresponding oxygen condition. Cells cultivated in physioxia were kept in low oxygen condition during treatment by capping each well with micro-caps, each micro-cap was removed for plasma treatment and immediately replaced. During all the treatment, the microwell plate was maintained at $37^{\circ} \mathrm{C}$ by a plate heater. After the treatment, intracellular fluorescence induced by RONS was measured with the microplate reader spectrofluorometer (excitation at $490 \mathrm{~nm}$; emission at $535 \mathrm{~nm}$ ).

\section{Data analysis and statistics}

One-way ANOVA and two-way ANOVA with Bonferroni's multiple comparison tests for the two oxygenation conditions were performed with GraphPad Prism 6. 


\section{RESULTS}

To evaluate the effect of CAP on oxygen dissolved in a liquid medium and on temperature, air-equilibrated DPBS, kept warm by a plate heater set to $37^{\circ} \mathrm{C}$, was treated at a frequency of 1 $\mathrm{kHz}$ with two different He flows: $0.5 \mathrm{~L} / \mathrm{min}$ and $1 \mathrm{~L} / \mathrm{min}$ (Fig. 1a). A typical experiment displaying the evolution of $\mathrm{pO}_{2}$ and temperature in DPBS before, during and after plasma treatment is shown in Figure 1b. Oxygen partial pressure decreases rapidly in the first seconds of treatment. The minimum reached at the end of the treatment remains stable for few seconds before recovering rapidly. Air-saturated DPBS $\left(18 \% \mathrm{O}_{2}\right)$ shows a $\mathrm{pO}_{2}$ between 150 and $200 \mathrm{mmHg}\left(19.7-26 \% \mathrm{O}_{2}\right)$ meaning that the ruthenium probe is oxygen saturated. Plasma treatment results in a rapid drop of $\mathrm{pO}_{2}$ to around $30 \mathrm{~mm} \mathrm{Hg}$ with $0.5 \mathrm{~L} / \mathrm{min} \mathrm{He}$ and to $25 \mathrm{~mm} \mathrm{Hg}$ with $1.0 \mathrm{~L} / \mathrm{min} \mathrm{He}$, which corresponds to 3 and $2.5 \%$ of oxygen, respectively. A drop to $2 \%$ and $1 \% \mathrm{O}_{2}$ is observed when DPBS is treated by He alone at $0.5 \mathrm{~L} / \mathrm{min}$ and $1.0 \mathrm{~L} / \mathrm{min}$, respectively (Fig. 1c).

Temperature also falls down during treatment with a speed rate not easy to measure due to the electromagnetic perturbation of the thermocouple signal during plasma operation. The final temperature value is clearly visible at the end when plasma is turned off. Plasma treatment with the two He flow rates has a cooling effect on DPBS leading the temperature to fall from $27^{\circ} \mathrm{C}$ to around $20-23^{\circ} \mathrm{C}$. Helium gas alone is able to cool down DPBS to $20^{\circ} \mathrm{C}$ at $0.5 \mathrm{~L} / \mathrm{min}$ and to $15^{\circ} \mathrm{C}$ at $1 \mathrm{~L} / \mathrm{min}$ (Fig. $1 \mathrm{~d}$ ). At the end of the treatment, DPBS temperature recovers slowly although the 96-well microplate is placed on a plate heater. The measured slow increase of temperature can be mainly attributed to the slow equilibrium dynamic between the small well volume and the plate heater separated by an air layer and also to the thermocouple thermal inertia [18]. We measured the ability of plasma to generate RONS in DPBS under $18 \%$ or $3 \% \mathrm{O}_{2}$ using different frequencies. During plasma treatment we measured a small evaporation of the DPBS: $7.7 \pm 1.2 \%$ with a He flow rate of $1 \mathrm{~L} / \mathrm{min}$ and $4 \pm 0.8 \%$ when medium was treated by plasma $0.5 \mathrm{~L} / \mathrm{min}$ of helium (data measured at different frequencies). In order to minimize medium evaporation during plasma treatment, we chose to feed plasma with a He flow rate of $0.5 \mathrm{~L} / \mathrm{min}$. Nitrite production was measured to evaluate nitrogen species formation and methylene blue discoloration to assess oxygen-derived species production. Fig. 2a shows CAP generated nitrites in DPBS equilibrated with $18 \%$ or $3 \% \mathrm{O}_{2}$. In atmospheric oxygen-equilibrated DPBS, nitrite production gradually increases together with the plasma delivered frequencies. In DPBS containing low oxygen, nitrite generation increases also with the frequency but producing significant smaller nitrite quantity compared to the more oxygenated DPBS. Methylene blue discoloration test was used to evaluate oxygen derived radicals formed upon plasma treatment.. The blue color solution is discolored by oxidation until it becomes transparent (leuco form). The dye is sensitive to reactive oxygen species such as $\mathrm{O}_{3}, \mathrm{O}_{2}^{-\bullet}$ [19] and it is also used to detect reactive species with a very short half-life time such as ${ }^{\circ} \mathrm{OH}$. [20]. ROS produced in DPBS upon plasma treatment increases gradually with the applied frequency in DPBS equilibrated with $18 \%$ of $\mathrm{O}_{2}$. Treatment of DPBS with lower percentage of dissolved $\mathrm{O}_{2}$ results in a similar increase of ROS for low frequencies and in a significant decrease compared to the airequilibrated DPBS when frequencies higher than $1.0 \mathrm{kHz}$ are applied (Fig. 2b). In order to exclude the role of UV in ${ }^{\circ} \mathrm{OH}$ photochemical formation, control experiments were performed using a $\mathrm{MgF}_{2}$ window (supplemental figure S1). To better understand the role of oxygen in reactive species generation, we also evaluated the effect of the CAP treatment in DPBS either air-equilibrated or air-bubbled $(0.24 \mathrm{~mL} / \mathrm{min})$. After the treatments, nitrites were measured in both conditions. Interestingly we found that air introduction in the liquid during plasma treatment increases nitrite formation (Fig. 3).

To assess the role of oxygen on the treatment of cell cultures by CAP, we measured intracellular RONS generated in two human skin cell lines, HaCaT keratinocytes and MSU 1.1 fibroblasts (Fig. 4 a-b). RONS formation inside cells upon plasma treatment was measured using the DCDHF-DA probe. Interestingly we found that, in basal condition, $\mathrm{HaCaT}$ and MSU 1.1 cells grown in $3 \% \mathrm{O}_{2}$ display already a lower level of intracellular RONS than the same cells raised in $18 \% \mathrm{O}_{2}$. For both cell lines, CAP treatment induced an increase in intracellular RONS production. The increase of frequency, between $0.25 \mathrm{kHz}$ and $1.25 \mathrm{kHz}$, results in a RONS increase, which is largely higher at $18 \% \mathrm{O}_{2}$ (about 2 -fold at $0.75 \mathrm{kHz}$ for both cell lines) when compared to $3 \% \mathrm{O}_{2}$. For higher frequency treatments, RONS generation shows a lower increase and the difference between both oxygen conditions is not significant.

\section{DISCUSSION}

Cold atmospheric plasmas with temperatures below $40^{\circ} \mathrm{C}$ are well suited for plasma medicine applications [21]. Our plasma gun showed a cooling effect on treated warm liquids (DPBS). As noted before, the DPBS temperature drop is bigger with helium flow alone. The slightly higher temperature obtained (3 to $5^{\circ} \mathrm{C}$ ) when plasma is "on" is due to the energy transferred from the plasma to the liquid, which partially compensates the DPBS cooling due to the gas flow. Oxygen measurement during CAP treatment showed an outgassing effect of DPBS. Oxygen content in atmospheric, air-equilibrated DPBS, $\left(18 \% \mathrm{O}_{2}\right)$ falls down to around $3 \%$ when the liquid is treated for $60 \mathrm{sec}$ at a $\mathrm{He}$ flow rate of $0.5-1.0 \mathrm{~L} / \mathrm{min}$. Similar $\mathrm{pO}_{2}$ values were measured using higher frequencies $1.5 \mathrm{kHz}$ and $2 \mathrm{kHz}$ with a flow rate of $0.5 \mathrm{~L} / \mathrm{min}$. With a He flow rate of $1 \mathrm{~L} / \mathrm{min}$, at the same higher frequencies, $\mathrm{pO}_{2}$ can drop to $10-15 \mathrm{~mm} \mathrm{Hg}\left(1.3-2 \%\right.$ of $\mathrm{O}_{2}$ ) (data not shown). The DPBS de-oxygenation induced by plasma is lower than the one observed when DPBS is treated with only helium gas at the same flow rate. CAP mitigation on helium sparging effect has already been observed by Oh and colleagues who attribute it to the oxidative species introduced in the medium by the plasma jet [14]. Using DPBS differently oxygenated $\left(18 \%\right.$ and $\left.3 \% \mathrm{O}_{2}\right)$, we evaluated the effect on RONS production of the CAP treatment using a helium flow rate of $0.5 \mathrm{~L} / \mathrm{min}$ and frequencies between 0.25 and $2.0 \mathrm{kHz}$. Nitrite increase in DPBS correlates with the increase of the applied frequency. Plasma treatment on DPBS with a lower percentage of dissolved oxygen generates a lower quantity of nitrites compared to DPBS containing $18 \% \mathrm{O}_{2}$ when treated at the same frequency. Similar results were found for ROS 
measurement assessed using methylene blue. ROS production increases proportionally with the applied frequencies in airexposed DPBS whereas in $3 \% \mathrm{pO}_{2}$ medium ROS generation significantly decreases for frequencies higher than $1.0 \mathrm{kHz}$. To explain the decrease of ROS observed at higher frequencies, we speculate that, during CAP treatment, two opposite effects occur. In one hand, helium degasses the liquid leading dissolved oxygen to the surface. In the other hand, the plasma plume flowing downward creates a drop in pressure on the surrounding air layer (Venturi effect). This negative pressure around the plume attracts air from outer layers so that atmospheric oxygen enters in contact with the plasma plume. At frequencies up to $1 \mathrm{kHz}$ the Venturi effect counterbalances the helium sparging effect, ROS are generated from oxygen coming from the liquid and oxygen coming from the attracted atmosphere. At higher frequencies plasma increases the helium flow preventing surrounding air to enter in contact with the plume, in this case ROS are mainly generated by oxygen coming from the DPBS. Recently Darny and colleagues have demonstrated how a negative polarity CAP at $1 \mathrm{kHz}$ generates a straight and stronger helium flow compared to the flow observed at lower frequencies [22]. Moreover oxygen was shown to play a dual role in CAP-induced RONS formation. Increasing quantities of oxygen $(0.1-2 \%)$ introduced directly in the helium feeding gas leads to a proportional decrease of ${ }^{\circ} \mathrm{OH}$ and nitrites/nitrates production in the plasma [23]. Reuter and colleagues demonstrated how a nitrogen-oxygen gas curtain placed around the plasma jet effluent influences nitrite generation in PBS. A linear increase in nitrites was observed when they used oxygen up to $50 \%$ and a decrease with higher oxygen percentages [24]. Here, our data suggest that oxygen dissolved inside the liquid medium can influence RONS production. The importance of tissue-dissolved oxygen and its influence on RONS generation and cell response upon plasma treatment has been already highlighted by $\mathrm{Oh}$ and colleagues in a soft agar skin model or in human skin cells [14, 25].

Although we found evidences of the influence of dissolved oxygen on reactive species generation, the differences measured are sometimes low between the two oxygenated conditions. This is mainly due to the small volume of the treated medium. Oxygen is in fact rapidly depleted even in DPBS equilibrated to the atmospheric air $\left(18 \% \mathrm{O}_{2}\right)$. To confirm our hypothesis, we measured nitrites generated during plasma treatment at three different frequencies, in air-balanced DPBS $(18 \%)$ or in DPBS continuously air-bubbled during the treatment. Plasma plume fed with oxygen coming from the airbubbled medium delivers higher quantities of nitrites when compared to medium only air-equilibrated that is rapidly depleted of oxygen in the first seconds of plasma treatment (Fig. 3). Oxygen partial pressure is a parameter that should be taken into account also in cell culture [1]. Oxygen is not only a source of reactive species during plasma treatment but its partial pressure can directly affect cell physiology [1, 26]. Our data showed that human skin cells maintained in physioxic conditions $\left(3 \% \mathrm{O}_{2}\right)$ generate a lower quantity of intracellular RONS compared to cells grown in an air-balanced medium. When treated by plasma, both cell lines respond to the treatment, increasing intracellular RONS generation with the increase of the applied frequency. The observed increase is significantly lower in cells maintained at $3 \% \mathrm{O}_{2}$ when frequencies between $0.25 \mathrm{kHz}$ and $1.25 \mathrm{kHz}$ are used (Fig. 4 ab). Treatment at frequencies between $1.5 \mathrm{kHz}$ and $2.0 \mathrm{kHz}$ showed not only no significant differences in cells exposed to both oxygenated conditions but also an inverted trend with intracellular RONS that decrease with the increase of frequency. The decrease of intracellular RONS at higher frequencies is coherent with the decrease of ROS measured in DPBS. Furthermore, although RONS generated in both cell lines appeared quantitatively lower in physioxia compared to normoxia condition, the CAP treatment at the different frequencies induces a higher relative increase of intracellular reactive species in physioxia compared to normoxia. Our results show how RONS generated by plasma treatment depend on the interplay of frequency and oxygen dissolved in the medium. The composition and the amount of generated reactive species can induce different physiological consequences on cells. RONS dose-dependent effect (hormesis) has already been demonstrated in HaCaT cells [27]. Moreover, in vivo plasma treatment was shown to increase oxygen release from the deeper layer of the treated tissue [28], gases coming from underneath blood vessels could also be a feeding source for RONS formation.

\section{CONCLUSION}

The control of helium flow rate, frequency and treatment duration is of great importance to generate the right dose of RONS and achieve the desired effect on a tissue. The same cell type could be positively stimulated or destroyed by CAP treatment. Our data suggest that tissue oxygenation should also be taken into account when planning a plasma treatment session. The intracellular RONS increase upon CAP treatment is very different when experiments are performed either in normoxic or in physioxic conditions. This underlines the very different stress response of the different cell lines but also the drastic impact of the oxygen level during plasma treatment. This may be of importance to design relevant in vitro skin cell plasma jet treatments likely to be translated to real in vivo protocols where tissue oxygenation levels are definitively different from those usually used during cell culture and experiments. The different intracellular RONS production achieved with the two different cell lines, also open up opportunities to select plasma treatment conditions likely to differentially activate/stimulate the different skin cells, which may be crucial for some biomedical applications.

\section{REFERENCES}

[1] A. Carreau, B. El Hafny-Rahbi, A. Matejuk, C. Grillon, and C. Kieda, "Why is the partial oxygen pressure of human tissues a crucial parameter? Small molecules and hypoxia," J Cell Mol Med, vol. 15, no. 6, pp. 1239-53, Jun, 2011.

[2] C. Grillon, A. Matejuk, M. Nadim, N. Lamerant-Fayel, and C. Kieda, "News on microenvironmental physioxia to revisit skin cell targeting approaches," Exp Dermatol, vol. 21, no. 10, pp. 723-8, Oct, 2012. 
[3] M. Nadim, S. Hassanaly, L. Dubannet, and C. Grillon, "Physioxia and microRNAs as key factors in the skin microenvironment," IFSCC Magazine, vol. 18, no. 1, pp. 3543, 2015-03, 2015.

[4] M. Valko, D. Leibfritz, J. Moncol, M. T. Cronin, M. Mazur, and J. Telser, "Free radicals and antioxidants in normal physiological functions and human disease," Int J Biochem Cell Biol, vol. 39, no. 1, pp. 44-84, 2007.

[5] C. C. Winterbourn, and A. J. Kettle, "Redox reactions and microbial killing in the neutrophil phagosome," Antioxid Redox Signal, vol. 18, no. 6, pp. 642-60, Feb 20, 2013.

[6] A. N. Onyango, "Endogenous Generation of Singlet Oxygen and Ozone in Human and Animal Tissues: Mechanisms, Biological Significance, and Influence of Dietary Components," Oxid Med Cell Longev, vol. 2016, pp. 2398573, 2016.

[7] A. J. Kettle, R. Turner, C. L. Gangell, D. T. Harwood, I. S. Khalilova, A. L. Chapman, C. C. Winterbourn, P. D. Sly, and C. F. Arest, "Oxidation contributes to low glutathione in the airways of children with cystic fibrosis," Eur Respir J, vol. 44, no. 1, pp. 122-9, Jul, 2014.

[8] C. Yang, H. Ling, M. Zhang, Z. Yang, X. Wang, F. Zeng, C. Wang, and J. Feng, "Oxidative stress mediates chemical hypoxia-induced injury and inflammation by activating NFkappab-COX-2 pathway in HaCaT cells," Mol Cells, vol. 31, no. 6, pp. 531-8, Jun, 2011.

[9] B. Uttara, A. V. Singh, P. Zamboni, and R. T. Mahajan, "Oxidative stress and neurodegenerative diseases: a review of upstream and downstream antioxidant therapeutic options," Curr Neuropharmacol, vol. 7, no. 1, pp. 65-74, Mar, 2009.

[10] S. J. Kim, and T. H. Chung, "Cold atmospheric plasma jetgenerated RONS and their selective effects on normal and carcinoma cells," Sci Rep, vol. 6, pp. 20332, Feb 03, 2016.

[11] M. Vandamme, E. Robert, S. Lerondel, V. Sarron, D. Ries, S. Dozias, J. Sobilo, D. Gosset, C. Kieda, B. Legrain, J. M. Pouvesle, and A. L. Pape, "ROS implication in a new antitumor strategy based on non-thermal plasma," Int. J. Cancer, vol. 130, no. 9, pp. 2185-94, May 01, 2012.

[12] D. B. Graves, "The emerging role of reactive oxygen and nitrogen species in redox biology and some implications for plasma applications to medicine and biology," J. Phys. D Appl. Phys., vol. 45, no. 26, pp. 263001, 2012.

[13] Y. Gorbanev, D. O'Connell, and V. Chechik, "Non-Thermal Plasma in Contact with Water: The Origin of Species," Chem. Eur. J.. 22, no. 10, pp. 3496-3505, Mar 01, 2016.

[14] J.-S. Oh, X. Strudwick, R. D. Short, K. Ogawa, A. Hatta, H. Furuta, N. Gaur, S.-H. Hong, A. J. Cowin, H. Fukuhara, K. Inoue, M. Ito, C. Charles, R. W. Boswell, J. W. Bradley, D. B. Graves, and E. J. Szili, "How plasma induced oxidation, oxygenation, and de-oxygenation influences viability of skin cells," Appl. Phys. Lett., vol. 109, no. 20, pp. 203701, 2016/11/14, 2016.

[15] E. Robert, V. Sarron, D. Riès, S. Dozias, M. Vandamme, and J. M. Pouvesle, "Characterization of pulsed atmosphericpressure plasma streams (PAPS) generated by a plasma gun," Plasma Sources Sci. Technol., vol. 21, no. 3, pp. 034017, 2012.

[16] P. Boukamp, R. T. Petrussevska, D. Breitkreutz, J. Hornung, A. Markham, and N. E. Fusenig, "Normal keratinization in a spontaneously immortalized aneuploid human keratinocyte cell line," J. Cell. Biol., vol. 106, no. 3, pp. 761-71, Mar, 1988.

[17] P. J. Hurlin, V. M. Maher, and J. J. McCormick, "Malignant transformation of human fibroblasts caused by expression of a transfected T24 HRAS oncogene," Proc Natl Acad Sci U S A, vol. 86, no. 1, pp. 187-91, Jan, 1989.

[18] T. Alexandros, W. Jens von, W. Bernhard, and O. Peter, "Thermocouple thermal inertia effects on impingement heat transfer experiments using the transient liquid crystal technique," Meas. Sci. and Technol., vol. 23, no. 11, pp. $115303,2012$.

[19] F. Huang, L. Chen, H. Wang, and Z. Yan, "Analysis of the degradation mechanism of methylene blue by atmospheric pressure dielectric barrier discharge plasma," Chem. Eng. J., vol. 162, no. 1, pp. 250-256, 2010.

[20] D. Yan, A. Talbot, N. Nourmohammadi, X. Cheng, J. Canady, J. Sherman, and M. Keidar, "Principles of using Cold Atmospheric Plasma Stimulated Media for Cancer Treatment," Sci. Rep., vol. 5, pp. 18339, Dec 17, 2015.

[21] G. Isbary, J. L. Zimmermann, T. Shimizu, Y. F. Li, G. E. Morfill, H. M. Thomas, B. Steffes, J. Heinlin, S. Karrer, and W. Stolz, "Non-thermal plasma-More than five years of clinical experience," Clin. Plasma Med., vol. 1, no. 1, pp. 1923, 2013/06/01/, 2013.

[22] T. Darny, J. M. Pouvesle, J. Fontane, L. Joly, S. Dozias, and E. Robert, "Plasma action on helium flow in cold atmospheric pressure plasma jet experiments," Plasma Sources Sci. Technol., vol. 26, no. 10, pp. 105001, 2017.

[23] S. A. Norberg, W. H. Tian, E. Johnsen, and K. M. J., "Atmospheric pressure plasma jets interacting with liquid covered tissue: touching and not-touching the liquid," J Phys D Appl Phys, vol. 47, no. 47, pp. 475203, 2014.

[24] S. Reuter, H. Tresp, K. Wende, M. U. Hammer, J. Winter, K. Masur, A. Schmidt-Bleker, and K. D. Weltmann, "From RONS to ROS: Tailoring Plasma Jet Treatment of Skin Cells," IEEE Trans. Plasma Sci., vol. 40, no. 11, pp. 29862993, 2012.

[25] J.-S. Oh, E. J. Szili, N. Gaur, S.-H. Hong, H. Furuta, H. Kurita, A. Mizuno, A. Hatta, and R. D. Short, "How to assess the plasma delivery of RONS into tissue fluid and tissue," $J$ Phys D Appl Phys, vol. 49, no. 30, pp. 304005, 2016.

[26] R. McCormick, T. Pearson, and A. Vasilaki, "Manipulation of environmental oxygen modifies reactive oxygen and nitrogen species generation during myogenesis," Redox Biol., vol. 8, pp. 243-251, 2016/08/01/, 2016.

[27] E. J. Szili, F. J. Harding, S.-H. Hong, F. Herrmann, N. H. Voelcker, and R. D. Short, "The hormesis effect of plasmaelevated intracellular ROS on HaCaT cells," J Phys D Appl Phys, vol. 48, 2015.

[28] G. Collet, E. Robert, A. Lenoir, M. Vandamme, T. Darny, S.Dozias, C. Kieda, and J. M. Pouvesle, "Plasma jet-induced tissue oxygenation: potentialities for new therapeutic strategies," Plasma Sources Sci. Technol., vol. 23, no. 1, pp. $012005,2014$. 


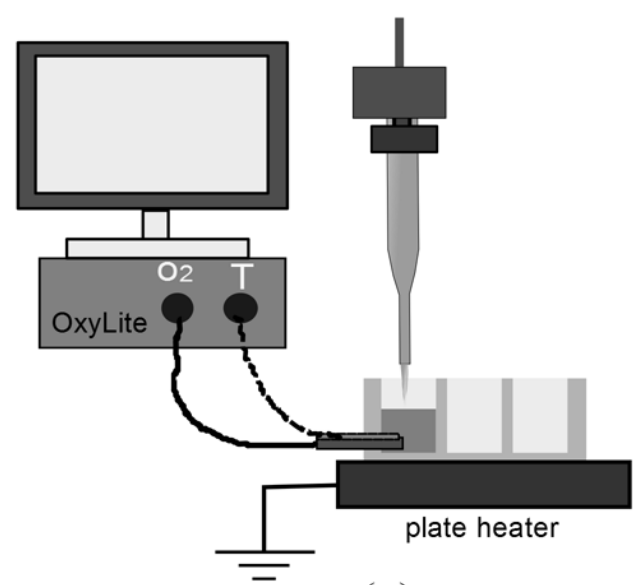

(a)

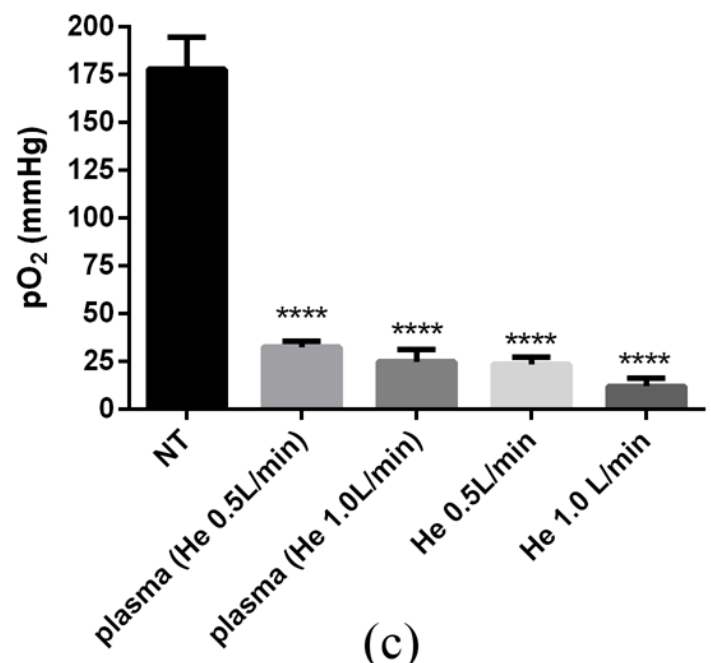

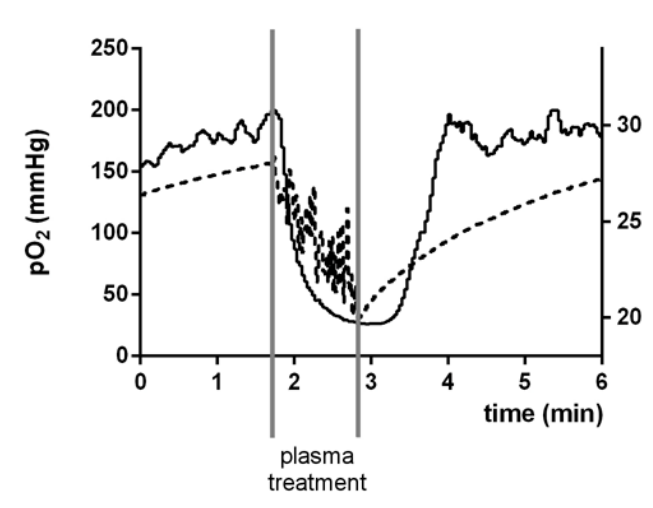

$-\mathrm{pO}_{2}$

-.. temperature

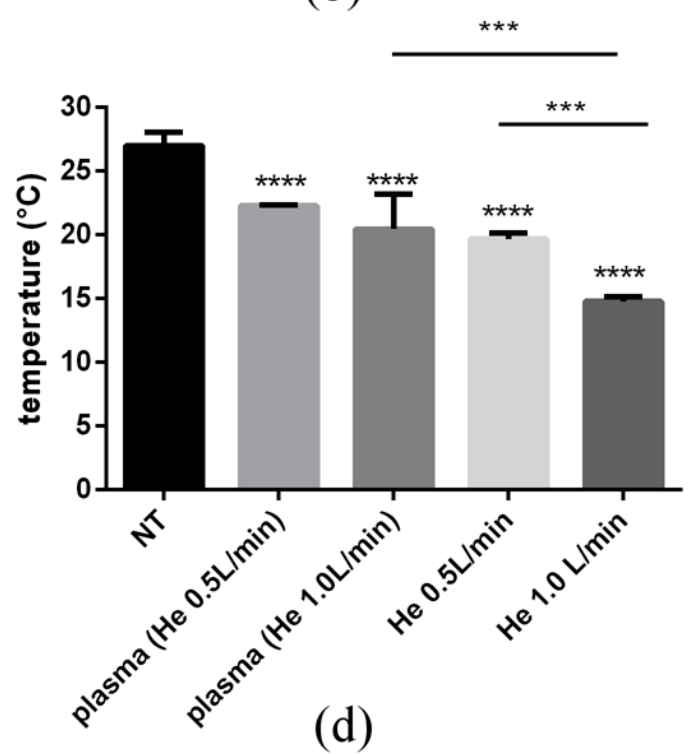

Fig. 1. Effect of CAP treatment on oxygen partial pressure in DPBS. DPBS was treated with CAP (frequency $1 \mathrm{kHz}$ ) or with helium alone for 1 min using two helium flows: 0.5 and $1 \mathrm{~L} / \mathrm{min}$. $\mathrm{pO}_{2}$ and temperature were monitored using OxyLite probes. (a) OxyLite system used to measure dissolved oxygen. (b) A typical experiment showing oxygen and temperature evolution during and after plasma treatment; (c) Effect of CAP or helium alone on oxygen partial pressure in DPBS; (d) Effect of CAP or helium alone on temperature in DPBS. Data are the mean \pm SD of $N=3$ independent experiments. One way ANOVA $* * * p \leq 0.001$, $* * * * \mathrm{p} \leq 0.0001$. 


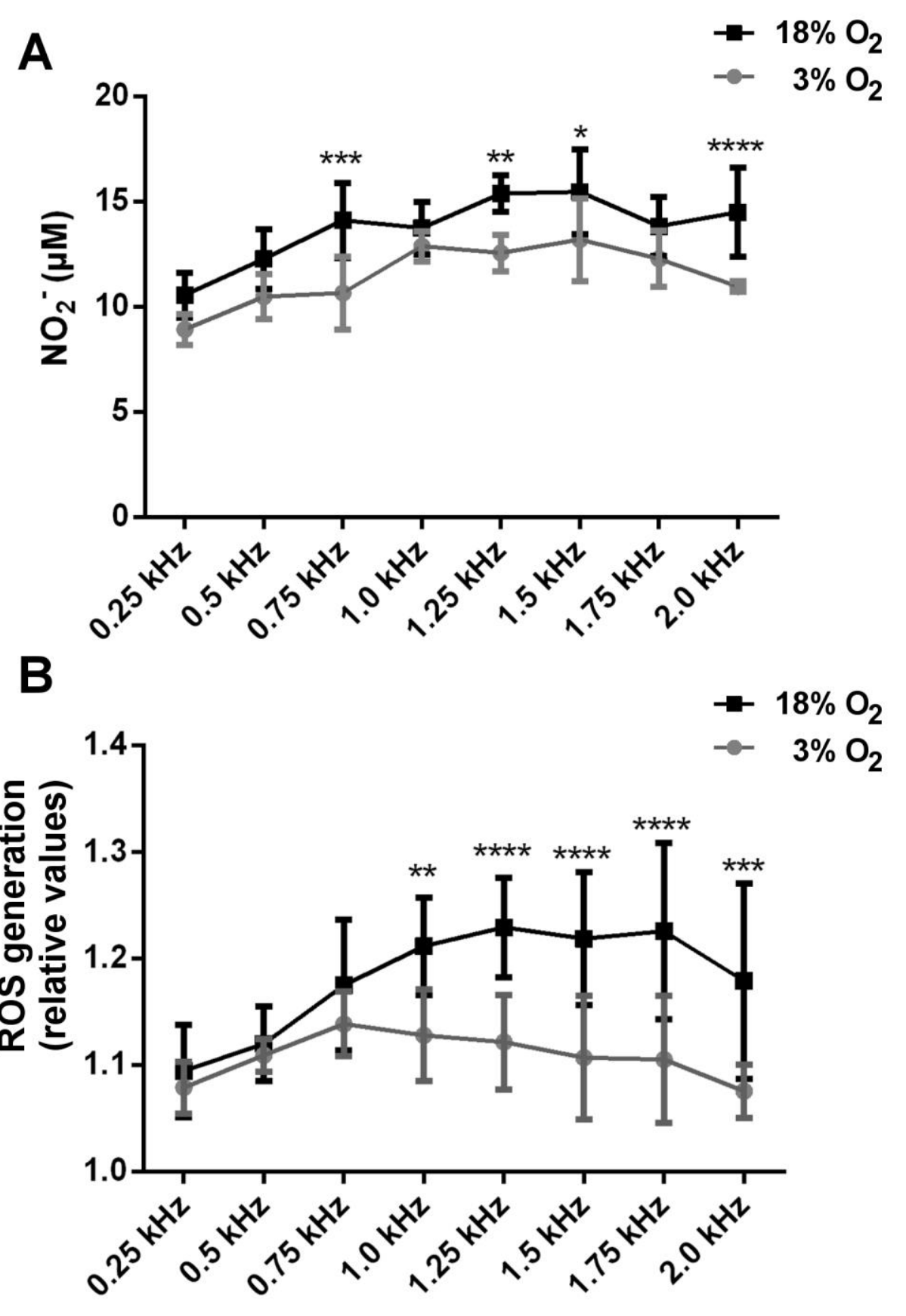

Fig. 2. Effect of CAP on RONS production in DPBS according to $\mathrm{pO}_{2}$. DPBS previoulsy equilibrated at 18 or $3 \% \mathrm{O}_{2}$ was treated by CAP using various frequencies. (a) Nitrite production measured by Griess test; (b) - $\mathrm{OH}$ radical production measured by methylene blue discoloration. Data are the mean $\pm \mathrm{SD}$ of $\mathrm{N}=3$ independent experiments (each experiment in triplicate). Two way ANOVA comparing frequency effect on the two oxygenation conditions $* \mathrm{p} \leq 0.05, * * \mathrm{p} \leq 0.01, * * * \mathrm{p} \leq 0.001$, and $* * * * \mathrm{p} \leq 0.0001$. 


\section{GRIESS TEST}

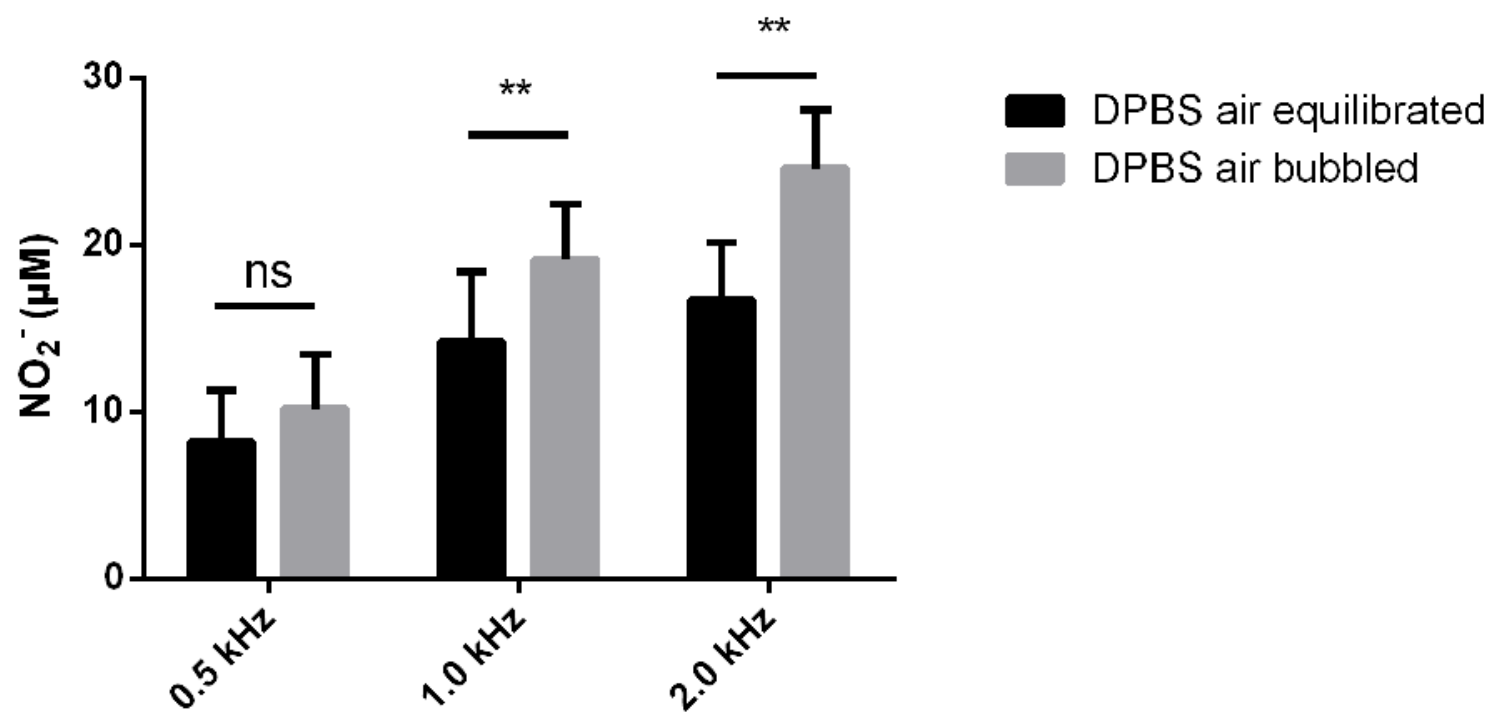

Fig. 3. Effect of CAP on nitrites formation in DPBS according to oxygen saturation. DPBS either airequilibrated or continuously air-bubbled were treated by CAP. Nitrites were measured by Griess test. Data are the mean \pm SD of $N=6$ independent experiments. One way ANOVA ** $\mathrm{p} \leq 0.01$ 


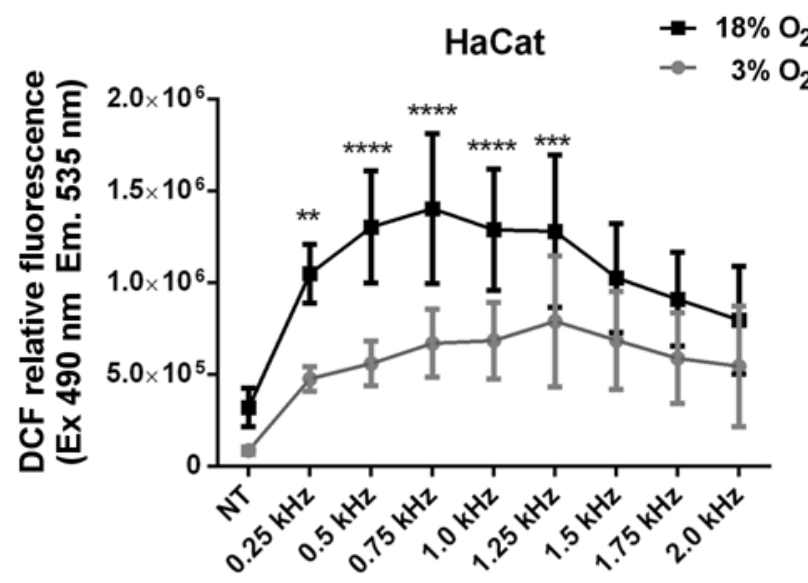

(a)

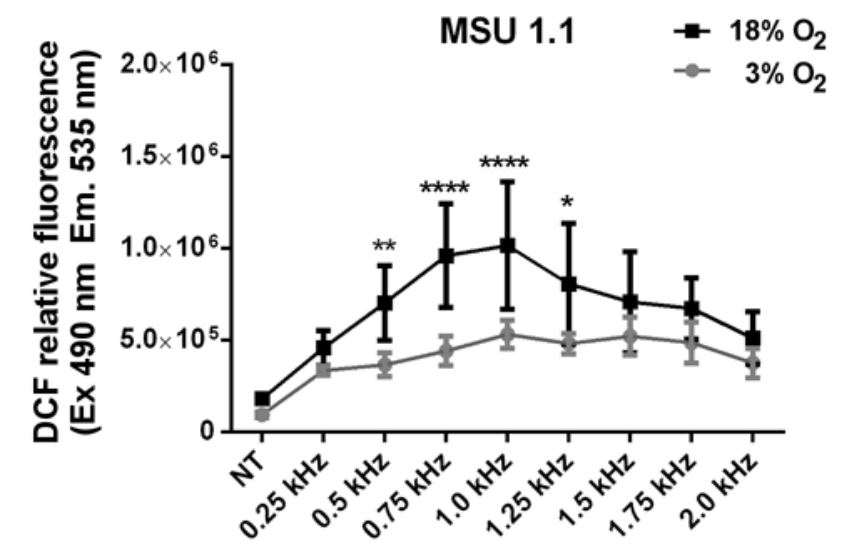

(b)

Fig. 4. Effect of CAP on intracellular RONS production by 2 human skin cell lines. Intracellular RONS production measured by DCF probe under plasma treatment at different frequencies in HaCaT (a) and MSU 1.1 (b) cultured either at $18 \%$ or $3 \% \mathrm{O}_{2}$. Data are the mean $\pm \mathrm{SD}$ of $\mathrm{N}=3$ independent experiments (each experiment in triplicate). Two way ANOVA comparing frequency effect on the two oxygenation conditions $* \mathrm{p} \leq 0.05, * * \mathrm{p} \leq 0.01, * * * \mathrm{p} \leq 0.001$, and $* * * * \mathrm{p} \leq 0.0001$. 